\title{
Comparative study of tubal patency by sonosalpingogram hysterosalpingography and diagnostic laparoscopy
}

\author{
Spoorthy Reddy, M. Padma*
}

Department of Obstetrics and Gynecology, Government Medical College, Mahabubnagar, Telangana, India

Received: 13 August 2019

Accepted: 19 August 2019

\section{*Correspondence:}

Dr. M. Padma,

E-mail: spurthi-mbbs@yahoo.co.in

Copyright: (c) the author(s), publisher and licensee Medip Academy. This is an open-access article distributed under the terms of the Creative Commons Attribution Non-Commercial License, which permits unrestricted non-commercial use, distribution, and reproduction in any medium, provided the original work is properly cited.

\begin{abstract}
Background: Sonosalpingography has been suggested as the first-line method to study tubal patency. This study is to bring into focus the value of pelvic sonogram in accessing tubal patency in order to overcome the radiation hazard associated with hysterosalpingogram reduce the cost of examination and encourage it at first-line office. Objective of this study was to compare the diagnostic efficacy of sonosalpingogram, hysterosalpingography and diagnostic laparoscopy for tubal patency as a cause for female infertility.

Methods: It is a prospective study in 100 patients attending for evaluation of infertility for a period of 2 years were chosen for this study. All cases with primary and secondary infertility who have attended infertility clinic for tubal causes.

Results: 68 cases were found to have bilateral patency as per SSG while 58 cases had bilateral patency as HSG. Similarly 24 cases had bilateral block as per SSG while 28 cases had bilateral block as per HSG. 8 cases had unilateral block as per SSG while 14 cases had unilateral block as per HSG. This difference in observations may probably attribute to tubal spasm in HSG. Bilateral patency was observed in 68 cases as against 64 cases in laparoscopy. Out of these 68 cases 9 cases were false positive as bilaterally patent. However bilateral blocks were shown to be 24 in both methods. Out of 12 cases of unilateral block as per laparoscopy 8 cases were detected by SSG. There was false negative rate of 5\%. There was false negative rate of $10 \%$ for tubal patency with HSG.

Conclusions: For low risk subjects for tubal factors in infertility, sonosalpingogram can be employed as a screening test of choice and for high risk subjects HSG and laparoscopy can be used.
\end{abstract}

Keywords: Diagnostic laparoscopy, Hysterosalpingography, Infertility, Screening test, Sonosalpingogram, Tubal patency

\section{INTRODUCTION}

One of the major problems of human reproduction that haunts many males and females is relative infertility, which affects $10-15 \%$ of reproductive age group. ${ }^{1}$ Infertility is defined as inability to conceive within one year of unprotected sexual Intercourse. Factors from either or both partners may contribute to difficulties in conceiving; therefore, it is important to consider all possible diagnoses before pursuing invasive treatment. Tubal factor fault occurs in $30-40 \%$ of female infertile patients, hence evaluation of tubal patency is essential in investigation of female infertility. Tubal factors not only contribute to major aetological factors but poses perplexing problems in diagnosis. Disorder of the tube may be pathological or functional. Pathological blockage can be secondary to any pelvic pathology particularly inflammatory in origin or it may be due to the congenital 
defects in the tube. ${ }^{1}$ But due to the development of microsurgical procedures, the diagnosis and management of the tubal factors has taken a new turn. The present study is a humble endeavour to establish the role of sonosalpingogram, hysterosalpingography and diagnostic laparoscopy in the evaluation of infertility. The objective of this study was to evaluate and compare the diagnostic efficacy of sonosalpingogram (hysterosonogram), hysterosalpingography and diagnostic laparoscopy for tubal patency as a cause for female infertility.

\section{METHODS}

It is a prospective study in 100 patients attending OPD department of gynecology and obstetrics for evaluation of infertility for a period of 2 years from October 2011 to September 2013 were chosen for this study.

\section{Inclusion criteria}

- All cases with primary and secondary infertility who have attended infertility clinic for tubal causes.

\section{Exclusion criteria}

- Active PID or recently treated PID within past three months, cases having active infections like pulmonary Koch's and presence of azoospermia or severe oligospermia in the semen of the husband.

Detailed history of all cases taken. Examination performed and recorded as in the proforma. Details of each procedure along with the possible complications were explained to the patients in their own language and consent taken for procedure. Detailed preliminary infertility work up done for all patients. They were called post menstrually after 4 days. SSG and HSG were done to assess the uterine cavity and patency of fallopian tube. Next day, diagnostic laparoscopy was done in all cases that had undergone HSG and SSG on the previous day and of both were compared.

The procedure was performed between days 6 and 12 of the menstrual cycle at least 48 hours after menses had ceased. The women were advised to avoid unprotected intercourse in this period. HSG was performed using a sterile technique. The patients were placed in a lithotomy position, and a vaginal speculum was inserted. The balloon catheter was inflated within the endocervical canal or lower uterine cavity. Approximately 10-15ml of a water-soluble contrast was injected manually through the cannula. Fluoroscopic examination was performed during the injection. Three x-ray films were taken; images of early and maximal opacification of the uterine cavity, fallopian tubes, and peritoneal contrast spillage were obtained. Prophylactic antibiotics were prescribed. The patients were routinely pre- medicated prior to the procedure with oral mefenamic acid $500 \mathrm{mg}$ three times per day until 48 hours after the procedure. The results of HSG were evaluated by radiologists.
Laparoscopy was performed under a general anaesthesia by an infertility specialist (the first researcher). A one $\mathrm{cm}$ incision was made within or just below the lower edge of the umbilicus. Through this incision the abdominal cavity is inflated with carbon dioxide gas and pneumoperitoneum being obtained. A trocar was inserted in the same region. The cannula of the trocar was left, and the trocar was pulled out. Then a laparoscope was introduced through the cannula. The abdominal cavity and pelvic were examined in the trendlenburg position. Atraumatic grasper forceps were used by the assistance of a second trocar for better visualization. A third trocar was applied if required. To assess tubal patency, methylene blue was injected through another uterine manipulator and results of laparoscopy were recorded by the infertility specialist as well. Demographic characteristics were collected through the interview using a structured questionnaire. Results of HSG and laparoscopy were also recorded in a check list by a trained midwife. Variables were age, primary and secondary infertility, duration of infertility, job, education, tubal patency (yes or no), bilateral no tubal patency and unilateral no tubal patency. Primary infertility describes couples who have never been able to become pregnant after at least one year of unprotected sexual cohabitation. Secondary infertility describes couples who have been pregnant at least once, but have not been able to become pregnant again. The Laparoscopy findings were used as a reference standard to calculate sensitivity, specificity, positive and negative predictive values for bilateral tubal no patency and unilateral or bilateral tubal no patency.

\section{Statistical analysis}

Data was analyzed was done in Microsoft excel, mean, $\mathrm{SD}$, percentages were calculated and tabulated.

\section{RESULTS}

Table 1: Demographic data in present study.

\begin{tabular}{|lll|}
\hline Age in years & Number of cases & Percentage \\
\hline $20-25$ & 34 & $34 \%$ \\
\hline $26-30$ & 52 & $52 \%$ \\
\hline $31-35$ & 12 & $12 \%$ \\
\hline $36-40$ & 2 & $2 \%$ \\
\hline Type of infertility & & $72 \%$ \\
\hline Primary infertility & 72 & $28 \%$ \\
\hline $\begin{array}{l}\text { Secondary } \\
\text { infertility }\end{array}$ & 28 & \\
\hline Menstrual & & $76 \%$ \\
\hline Regular cycle & 76 & $22 \%$ \\
\hline Oligomenorrhoea & 22 & $2 \%$ \\
\hline Polymenorrhoea & 2 & \\
\hline
\end{tabular}

Majority of cases in our study were between the age group of 26-30 years (52\%). 
Minimum age was 21 years and maximum age was 46 years.

Out of 100 cases included in study, 72 cases had primary infertility, 28 cases had secondary infertility.

$76(76 \%)$ cases had presented with regular menstrual cycle and the remaining $24(24 \%)$ had irregularities in the menstrual cycle. Among the 22 cases had oligomenorrhoea and only 2 cases had polymenorrhoes.

Table 2: Causes of secondary infertility and pathology associated.

\begin{tabular}{|lll|}
\hline Causes & Number of cases & Percentage \\
\hline Post-abortal/delivery & 16 & $57.00 \%$ \\
\hline H/o PID & 8 & $28.50 \%$ \\
\hline Unknown & 4 & $14.20 \%$ \\
\hline Type of pathology & & \\
\hline Vulvitis & - & - \\
\hline Cervicitis & 20 & $20 \%$ \\
\hline Vaginitis & 4 & $4 \%$ \\
\hline Pin hole OS & 4 & $4 \%$ \\
\hline
\end{tabular}

In 28 cases with secondary infertility, 16 cases had previous deliveries or abortions, 8 cases had PID and 4 cases had no significant history.

On examination, 20 cases had cervicitis, 4 cases had vaginitis, 4 cases had pin hole OS.

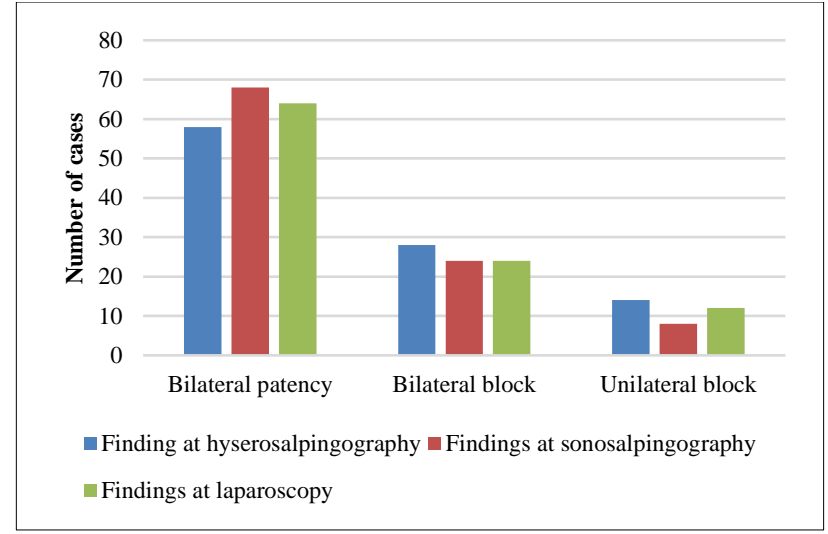

Figure 1: Finding at hyserosalpingography, sonosalpingography and laparoscopy.

In 100 cases studied, 58 cases had bilateral patency 28 cases had bilateral block 14 cases had unilateral block (right or left), Hydrosalpinx noted-2 cases. All these cases were subjected to sonosalpingography and diagnostic laparoscopy and these findings were carefully compared and the degree of agreement was carefully noted.

There was bilateral spilling and fluid in POD showing bilateral patency in 68 cases. There was collection in POD and unilateral spillage in 8 cases.

On laparoscopy, Bilateral tubal patency was observed in 64 cases, Bilateral block in 24 cases and Unilateral block in 12 cases.

Table 3: Comparative study of hyserosalpingography, sonosalpingography and laparoscopy.

\begin{tabular}{|llll|}
\hline Observation & SSG & HSG & Correlation in percentage \\
\hline Bilateral patency & 68 & 58 & $85 \%$ \\
\hline Bilateral block & 24 & 28 & $86 \%$ \\
\hline Unilateral block & 8 & 14 & $87 \%$ \\
\hline & SSG & Laparoscopy & Correlation in percentage \\
\hline Bilateral patency & 68 & 64 & $94 \%$ \\
\hline Bilateral block & 24 & 24 & $100 \%$ \\
\hline Unilateral block & 8 & 12 & $67 \%$ \\
\hline & HSG & Laparoscopy & Correlation in percentage \\
\hline Bilateral patency & 58 & 64 & $90.6 \%$ \\
\hline Bilateral block & 28 & 24 & $85.5 \%$ \\
\hline Unilateral block & 14 & 12 & $85.5 \%$ \\
\hline
\end{tabular}

68 cases were found to have bilateral patency as per SSG while 58 cases had bilateral patency as HSG. Similarly 24 cases had bilateral block as per SSG while 28 cases had bilateral block as per HSG. 8 cases had unilateral block as per SSG while 14 cases had unilateral block as per HSG. This difference in observations may probably attributed to tubal spasm in HSG
Laparoscopy is considered gold standard for diagnosing tubal patency and SSG is compared with laparoscopy.

Bilateral patency was observed in 68 cases as against 64 cases in laparoscopy. Out of these 68 cases 9 cases were false positive as bilaterally patent. However bilateral blocks were shown to be 24 in both methods. Out of 12 
cases of unilateral block as per laparoscopy 8 cases were detected by SSG. There was false negative rate of $5 \%$.

58 cases were shown to have bilateral patency in HSG as against 64 cases in laparoscopy. However out of these 58 cases there were 4 false positives. 28 cases were shown to have bilateral block and 14 cases were shown to have unilateral block with HSG. There was false negative rate of $10 \%$ for tubal patency with HSG.

\section{DISCUSSION}

Infertility is defined as inability to conceive within one year of unprotected sexual intercourse. The overall prevalence for this condition is about $10-15 \%$ in couples of reproductive age. Female factor attributes in about 40 $45 \%$ of cases and male factor is reported in about $25-40 \%$ cases, whereas $10 \%$ cases can have unexplained infertility. One third of infertility cases are due to anatomical abnormalities of the female reproductive tract such as tubal blockage. Tubal factors accounts for 30$40 \%$ cases of infertility in females. ${ }^{6,8}$ The degree of tubal pathology determines the possibility for fertility. The evaluation of the fallopian tube is necessary to determine the management plan of infertility. A number of diagnostic tests are being used in clinical practice to assess tubal patency as part of the work-up for infertility. The three most important diagnostic procedures which are used for the evaluation of tubal patency are hysterosalpingography (HSG) and laparoscopy and sonosalpingography. Hysterosalpingography and laparoscopy are the 2 classic investigative methods in the assessment of tubal patency in infertile women, but in addition to the identified benefits, each method also carries the risk of severe adverse effects. Hysterosalpingography as an outpatient procedure is relatively inexpensive, does not require general anesthesia, and is associated with a therapeutic effect.
Unlike laparoscopy, HSG enables a view within the uterine cavity and fallopian tubes. Nevertheless, this procedure is rather painful and is associated with exposure to ionizing radiation and its related risks. A substantial number of obstructions detected on HSG are not based on actual tubal conditions but are due to a transient spasm. Laparoscopy is a more invasive procures that requires general anesthesia. It is associated with the risk of accidental injury of the intestine, urinary bladder, and pelvic vessels, but at the same time, this method provides valuable information about the pelvic anatomy that cannot be obtained during HSG. With the advent of ultrasound, Sonosalpingography has gained importance in diagnosing tubal patency. Sonosalpingography can be provided in an outpatient setting, and it is associated with minimal patient discomfort and a low risk of infection. This procedure is noninvasive and rather easy to perform in almost any medical setting because it does not require sedation or anesthesia nor does it have any adverse effects or complications. It can be used as both a diagnostic tool and a therapeutic method in an infertile patient with tubal infertility. The sensitivity, specificity of these techniques varies widely from study to study with considerable false positive and false negative rates. Nevertheless, laparoscopy is considered gold standard in the diagnosis of infertility. This study was designed to evaluate the diagnostic accuracy of the minimally invasive and/or noninvasive techniques compared to the laparoscopic methodology and to determine their advantages and disadvantages of one over the other technique.

In the present study 100 female patients attending to the infertility we evaluated for detecting the tubal factors in infertility by using three different modalities which include transvaginal saline sonosalpingography, hysteosalpingography with iodine contrast and laparoscopy with chromopertubation.

Table 4: Type of infertility in various studies in comparison with our study.

\begin{tabular}{|c|c|c|c|c|c|}
\hline Infertility & Foroozanfard et $\mathrm{al}^{2}$ & Subarata $\mathrm{L}$ et $\mathrm{al}^{3}$ & Samal S et al ${ }^{4}$ & Suttipichate $\mathrm{J}$ et $\mathrm{al}^{5}$ & Present study \\
\hline Primary & 69 & 73 & 75 & 75 & 75 \\
\hline Secondary & 31 & 27 & 25 & 25 & 25 \\
\hline
\end{tabular}

Table 5: Age distribution in various studies in comparision with our study.

\begin{tabular}{|lllll|}
\hline Age distribution in years & Samal S et a ${ }^{4}$ & Subrata L et al & Shetty SK et al & Present study \\
\hline $20-25$ & 57.5 & 20 & 18 & 34 \\
\hline $26-30$ & 33.75 & 38 & 36 & 52 \\
\hline $31-35$ & 5 & 35 & 34 & 12 \\
\hline $36-40$ & 3.75 & 8 & 12 & 2 \\
\hline
\end{tabular}

Majority of the patients $(75 \%)$ in our study presented with primary infertility and only $25 \%$ of patients with secondary infertility (Table 1). This correlates well with the studies conducted by Samal et al, and Suttipichate et al where the primary and secondary infertility was $75 \%$ and $25 \%$ in both the studies. ${ }^{4,5}$ Other studies with similar presentation include Foroozanfard et al and subrata et al where the primary and secondary infertility was $69 \%$ and 
$31 \%, 73 \%$ and $27 \%$ respectively. ${ }^{2,3}$ Contrary to our study, in a study conducted by Eleje et al, majority were presented with secondary infertility $(76.5 \%)$ and only $23.5 \%$ being primary infertility. ${ }^{6}$ This may be due to geographical variation related to a particular area where STI's and pelvic inflammatory diseases are more prevalent and also early marriages are more common (Table 2).

Table 6: Sonosalpingography, hysterosalpingography and laparoscopy findings in comparison with our study.

\begin{tabular}{|c|c|c|c|c|c|}
\hline Sonosalpingography finding & Samal S et al ${ }^{4}$ & Subrata $\mathrm{L}$ et $\mathrm{al}^{3}$ & 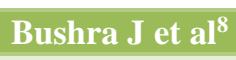 & Yeshita $\mathbf{P}$ et $\mathbf{a l}^{9}$ & Present study \\
\hline Bilateral patency & 62.5 & 73 & 53 & 75.5 & 68 \\
\hline Bilateral block & 12.5 & 7 & 13 & 11.3 & 24 \\
\hline Unilateral block & 25 & 20 & 34 & 13.2 & 8 \\
\hline \multicolumn{6}{|c|}{ Hysterosalpingography findings } \\
\hline Bilateral patency & 52.5 & 71 & 38 & 69.4 & 58 \\
\hline Bilateral block & 18.75 & 9 & 31 & 16.1 & 28 \\
\hline Unilateral block & 28.75 & 20 & 31 & 14.5 & 14 \\
\hline \multicolumn{6}{|l|}{ Laparoscopy findings } \\
\hline Bilateral patency & 66.25 & 75 & 53 & 72.6 & 64 \\
\hline Bilateral block & 13.75 & 6 & 8 & 11.3 & 24 \\
\hline Unilateral block & 20 & 19 & 39 & 16.1 & 12 \\
\hline
\end{tabular}

Table 7: Sonography versus laparoscopy in comparison with our study.

\begin{tabular}{|c|c|c|c|c|c|}
\hline Parameter & $\begin{array}{l}\text { Ranaweera AKP } \\
\text { et al }^{10}\end{array}$ & 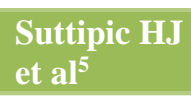 & $\begin{array}{l}\text { Hajishafiha } \\
\text { et al }{ }^{11}\end{array}$ & $\begin{array}{l}\text { Chan CC } \\
\text { et al }{ }^{12}\end{array}$ & $\begin{array}{l}\text { Present } \\
\text { study }\end{array}$ \\
\hline Sensitivity & 84.9 & 96.97 & 94 & 100 & 92.1 \\
\hline Specificity & 81.8 & 88.89 & 100 & 67 & 75 \\
\hline Positive predictive value & 96.8 & 96.97 & 100 & 89 & 86.8 \\
\hline Negative predictive value & 45 & 88.89 & 75 & 100 & 84.4 \\
\hline
\end{tabular}

Table 8: Hysterosalpingography versus laparoscopy in comparison with our study.

\begin{tabular}{|c|c|c|c|c|c|}
\hline Parameter & Foroozanfard et $\mathrm{al}^{2}$ & Sakar MN et al ${ }^{13}$ & Jara D et a $\mathbf{l}^{14}$ & Sarwat R et al ${ }^{15}$ & $\begin{array}{l}\text { Present } \\
\text { study }\end{array}$ \\
\hline Sensitivity & 92.1 & 63 & 77.4 & 90.9 & 84 \\
\hline Specificity & 85.7 & 89.3 & 80.2 & 89.4 & 88.8 \\
\hline Positive predictive value & 97.2 & 92 & 79.7 & 83.3 & 93.1 \\
\hline Negative predictive value & 66.7 & 55 & 78.1 & 55.5 & 76.1 \\
\hline
\end{tabular}

In the present study, majority of the patients were in the age group of 26 to 30 years $(52 \%)$. This correlates well with the studies conducted by Subrata et al, and Shetty et al where the predominant age group was 26 to 30 years constituting $38 \%$ and $36 \%$ of the total patients respectively. ${ }^{3}$ Next to this, the common age group was 20 to 25 years $(34 \%)$ followed by the age group 31 to 35 $(12 \%)$. Patients above 35 years of age were not common, contributing only $2 \%$ of the total patients. These findings also correlate well with the above mentioned studies.

In the present study, sonosalpingography identified that $68 \%$ of patients are having bilateral tubal patency. This finding is similar to the studies done by Samal et al and Subrata et al, where the bilateral patency was $62.5 \%$ and $73 \%$ respectively. ${ }^{3,4}$ The total blocks (both unilateral and bilateral) identified were $32 \%$ which is similar to the studies by Samal et al and Subrata et al. ${ }^{4}$ But when the unilateral or bilateral blocks were considered separately our findings were contrary to the above studies. In our study bilateral blocks were more common (24\%) than unilateral blocks $(8 \%)$ but in all the above mentioned studies unilateral block was more commonly seen followed by bilateral blocks (Table 3 and Figure 1).

In the present study, hysterosalpingography findings included $58 \%$ bilateral patency followed by $28 \%$ bilateral blocks and then $14 \%$ unilateral blocks. These findings were similar to the findings if Foroozanfard et al where majority were having bilateral patency $(69.4 \%)$ followed by bilateral and unilateral blocks (16.1\% and $14.5 \%)$. Samal et al and Subrata et al studies also showed similar findings with regards to the bilateral patency which was the predominant finding (52.5\% and $71 \%$ respectively). 
But with respect to blocks, unilateral blocks were more common than bilateral blocks in both these studies $(28.75$ and $18.75,20$ and 9 respectively).

Laparoscopy, which is considered as gold standard methodology proved that majority of the patients were having bilateral patent fallopian tubes $(64 \%)$. This finding is similar to the laparoscopic findings of the studies by Samal et al and Foroozanfard et al where bilateral patencies were $66.25 \%$ and $72.6 \%$ respectively. ${ }^{2,4}$ Next to this, bilateral blocks were more commonly seen in our study $(24 \%)$ followed by unilateral blocks $(12 \%)$. This is somewhat contrary to the above studies where unilateral blocks occurred more frequently than bilateral.

Considering the laparoscopy as the gold standard, the Sonoslapingography findings in our study with respect to the tubal patency had a sensitivity and specificity of $92.1 \%$ and $75 \%$ respectively. These findings correlate with the studies by Ranaweera et al, and suttipichate et al where the sensitivity of the sonosalpingography was higher than specificity $(84.9 \%$ and $81.8 \%, 96.97 \%$ and $88.89 \%$ respectively). ${ }^{5,10}$ The positive and negative predictive values of sonosalpingography in our study were 86.8 and $84.4 \%$. These findings were similar to the findings of Suttipichate et al where the positive and negative predictive values were 96.97 and $88.89 \%$ respectively. ${ }^{5}$

In the present study, the sensitivity and specificity of the hysterosalpingography in detecting the tubal patency was $84 \%$ and $88.8 \%$ which is comparable to the studies conducted by Rizvi $\mathrm{S}$ et al and Diaz $\mathrm{J}$ et al where the sensitivity and specificity were 90.9 and 89.4, 77.4 and 80.2 respectively. ${ }^{14,15}$ The positive and negative predictive values of hysterosalpingography in our study were 93.1 and $76.1 \%$. This finding is similar to the findings of Foroozanfard et al and Sarkar MN et al where the positive and negative predictive values were 97.2 and $66.7 \%, 92$ and $55 \%$ respectively. ${ }^{2,13}$

\section{CONCLUSION}

Sonosalpingogram is offered not as a substitute for HSG, laparoscopy, hysteroscopy but as an office screening technique for tubal patency, which is simple, minimally expensive and the one which is complimentary to the armemantarium of infertility investigations already available. It can be done at the same time as pelvic examination in gynaecologist's office and gives additional information about pelvic pathology. HSG still remains to be simple, sensitive and cost effective. Additional benefits of sonosalpingogram over HSG are it can note pelvic factors, exact site of tubal block can be evaluated, no radiation hazard and no admission.

For low-risk subjects for tubal factors in infertility, sonosalpingogram can be employed as a screening test of choice and for high risk subjects HSG and laparoscopy can be used. However laparoscopy still remains gold standard method for evaluation of tubal factors in infertility.

Funding: No funding sources

Conflict of interest: None declared

Ethical approval: The study was approved by the Institutional Ethics Committee

\section{REFERENCES}

1. Klein, Jeffrey and Sauer, Mark. Assessing fertility in women of advanced reproductive age. Am J Obstet Gynecol. 2001;185:758-70.

2. Foroozanfard F, Rafiei H, Samimi M, Gilasi HR, Gorjizadeh R, Heidar Z, et al. The effects of dietary approaches to stop hypertension diet on weight loss, anti-Müllerian hormone and metabolic profiles in women with polycystic ovary syndrome: A randomized clinical trial. Clinical Endocrinol. 2017;87(1):51-8.

3. Lalls SS, Debdulta G, Debdas S. Comparative evaluation of sonosalpingography hysteronsalpingography and laproscopy for determination of tubal patency. J Obstet Gynecol India. 2007;57(2):158-61.

4. Samal S, Agrawal S, Agrawal M. Role of laparoscopy in infertility in a rural setup hospital. Int J Reprod Contracept Obstet Gynecol. 2014;3:185-8.

5. Suttipichate J, Sroywattana C, Dejthevaporn T. Transvaginal saline sonosalpingography for the assessment of tubal patency. Thai J Obstet Gynaecol. 2002;14:223-9.

6. Eleje, George Ei, Okaforcha Umeononihu, Osita Udegbunam, Onyebuchi Etoniru, Izu Okwuosa, Ayodele. Hysterosalpingographic findings among infertile women: review at a tertiary health care institution in Nnewi, South-east Nigeria. Afrimedic J. 2012;13:20-3.

7. Shetty SK, Shetty H, Rai S. Laparoscopic evaluation of tubal factor in cases of infertility. Int $\mathrm{J}$ Reprod Contracept Obstet Gynecol. 2013;2(3):410-3.

8. Al-Rubaii, Jabber B. Comparative evaluation of saline-sonograghy hystro-salpingograghy and laprascopy in determination of tubal patency. 2011

9. Pujar, Yeshita, Sherigar B, Patted S, Desai BR, Dhumale H. Comparative evaluation of saline infusion sonohysterography and hysterolaparoscopy for diagnosis of uterine cavity abnormalities and tubal patency in infertility: a one year cross-sectional study. J SAFOG with DVD. 2011:133-135.

10. Ranaweera AKP, Batcha M, Kalansooriya H. Value of sonographic hydrotubation using agitated saline as a screening test for tubal patency: Sch J App Med Sci. 2013;1(2):122-30.

11. Hajishafiha M, Zobairi T, Zanjani VR, Ghasemi-Rad M, Yekta Z, Mladkova N. Diagnostic value of sonohysterography in the determination of fallopian tube patency as an initial step of routine infertility assessment. J Ultrasound Med. 2009;28(12):1671-7. 
12. Ng EH, Chan CC, Tang OS, Yeung WS, Ho PC. Factors affecting endometrial and subendometrial blood flow measured by three-dimensional power Doppler ultrasound during IVF treatment. Hum Reprod. 2006;21(4):1062-9.

13. Sakar MN, Unal A, Atay AE, Zebitay AG, Verit FF, Demir $S$, et al. Is there an effect of thyroid autoimmunity on the outcomes of assisted reproduction?, J Obstet Gynaecol. 2016;36(2):213-7.

14. Jara-Díaz S, Tovar B, Trujillo L. Marginal costs, scale and scope for cargo handling firms in Spain. Transportation. 2005;32:275-91.
15. Rizvi S, Jafri A, Haider R. Tubal sterilization reversal: is there any role in this modern era of art?. Ann King Edward Med Univer. 2015;21(4):290.

Cite this article as: Reddy S, Padma M. Comparative study of tubal patency by sonosalpingogram

hysterosalpingography and diagnostic laparoscopy. Int J Reprod Contracept Obstet Gynecol 2019;8:3435-41. 